\title{
Inventarisasi Jenis Ikan Bakau Di Teluk Pangpang Taman Nasional Alas Purwo Banyuwangi
}

\author{
Meita Asrul Rofiqoh, Tristi Indah Dwi Kurnia, Fitri Nurmasari \\ Program Studi Biologi, Fakultas Matematika dan Ilmu Pengetahuan Alam \\ Universitas PGRI Banyuwangi \\ Email: meitaardiawati@gmail.com
}

\begin{abstract}
The forest of mangrove in the area of Pangpan Blok in Jati Papak TNAP have mangrove of the fores. There are many natural activity of fish in the forest of mangrove. Research carried to determine the types of mangrove fish, knowing the density and diversity of mangrove fish that were in the Gulf region Pangpang the block in Jati Papak Alas Purwo National Park. The research conducted was in MayJune 2016. This type of research is quantitative descriptive. The workings are used in this research include determining the location, fish sampling, measurements of abiotic parameters. Analysis of the data used in quantitative indices which include the density and diversity of species. Based on the results of the study, the types of fish that was obtained in the Gulf region Pangpang the Block in Jati Papak Alas Purwo National Park is family and 6 species. The results of the highest density value is kind periothalamus $s p$ to the value of density 4.92, density the lowest skor is kind sardinella longiceps with a density value of 0.56 , and the value of the relative density $(\mathrm{KR})$ is the highest of species with density values $(\mathrm{kr}) 1,99$ and density relative value (KR) sardinella longiceps lowest with a value of 0.23 . The results of the analysis of mangrove fish diversity at every station indicate that the diversity of fish species Pangpang Gulf region the Block in Papak Alas Purwo National Park is relatively low, at station 1 value ranging between $\mathrm{H}$ ': 0.36645 at station 2 values ranged between H': 0 , 35934 and in satasiun 3 values ranged between $H^{\prime}: 0.36266$.
\end{abstract}

Keywords: Inventory, fish type, density, diversity.

\section{PENDAHULUAN}

Hutan mangrove merupakan salah satu bentuk keanekaragaman hayati yang memiliki ekosistem hutan yang unik dan khas dengan didominasi oleh beberapa spesies pohon atau semak-semak yang mempunyai kemampuan untuk tumbuh dalam perairan asin Nyibakken, (1982). Keberadaan mangrove di kawasan tersebut memiliki peran penting sebagai perlindungan fisik untuk garis pantai, bagi beberapa jenis juvenil yang terdapat di kawasan Teluk Pangpang terdapat jenis ikan, namun belum di ketahuai jenis-jenis ikan apa saja yang sering dijumpai di hutang mangrove. 
Perlu adanya berbagai studi tersebut dapat menambah data jenis ikan yang berasosiasi dengan hutan mangrove. Oleh karena itu peneliti ingin melakukan penelitian di hutan mangrove Teluk Pangpang Taman Nasional Alas Purwo dengan judul "Inventarisasi Jenis Ikan Bakau di Teluk Pangpang Taman Nasional Alas Purwo Banyuwangi".akibat adanya erosi dan pasang surut yang membawa nutrien pada wilayah estuari tersebut $\mathrm{g}$ dalam rantai makanan untuk kesetabilan ekosistem, sskarena dapat mendukung kehidupan hewan lain yang lebih tinggi trofiknya (Irwanto, 2006).

\section{METODE PENELITIAN}

Lokasi pengambilan sampel berada di kawasan Teluk Pangpang Blok Jati Papak Taman Nasional Alas Purwo. Penentuan lokasi penelitian ditentukan berdasarkan survey lapangan dan kondisi ekosistem mangrove yang berada di Blok Jati Papak Taman Nasional Alas Purwo. Teknik sampling dalam penelitian ini adalah purposive random sampling dengan intensitas yang digunakan sebesar 3\% dari luas areal mangrove. Pengambilan sampel mengunakan jala ukuran $25 \mathrm{~m} \times 1 \mathrm{~m}$ jala di pasang pada saat air surut. Sampel jenis-jenis ikan di kumpulkan dan di ambil 1 ekor dari masing-masing jenis untuk di jadikan sampel (Eddy, 2013).

\subsection{Analisis Data}

Anilisis data yang di gunakan secara kuantitatif meliputi indeks kepadatan, kepadatan relatif (KR) jenis ikan dan keanekaragaman ikan. kepadatan $(\mathrm{K})$

a. indeks kepadatan

$$
K=\frac{\mathrm{ni}}{\mathrm{A}}
$$

Dimana :

$$
\begin{aligned}
& \mathrm{K}=\text { kepadatan suatu jenis } \\
& \mathrm{ni}=\text { jumlah individu suatu jenis } \\
& \mathrm{A}=\text { luas jala (Krebs, 1985) }
\end{aligned}
$$

b. Kepadatan Relatif (KR) 


$$
K R(\%)=\frac{n i}{\Sigma \mathrm{N} \times 100 \%}
$$

Diamana :

ni $=$ jumlah individu suatu jenis

$\sum \mathrm{N}=$ total seluruh individu (Krebs, 1985).

c. Keanakeragaman Shannon Wienner

$$
H^{*}=\sum_{i=1}^{s} p i \ln p i
$$

Keterangan :

$$
\begin{aligned}
& \mathrm{H}^{\prime}=\text { Indeks Keanekaragaman Shannon Wienner } \\
& \mathrm{p}=\mathrm{ni} / \mathrm{N} \text { (perbandingan jumlah individu suatu jenis dengan seluruh jenis) } \\
& \mathrm{ln}=\text { Logaritma Natural (Shannon Wiener, } 1987 \text { ) }
\end{aligned}
$$

\section{HASIL DAN PEMBAHASAN}

\subsection{Jenis Ikan yang Ditemukan}

Tabel 3.1 Jenis Ikan

\begin{tabular}{llllc}
\hline No & Ordo & Famili & Genus & Spesies \\
\hline 1. & Mugiliformes & Mugilidae & Valaugil & $\begin{array}{c}\text { Valamugil seheli } \\
\text { (Forskkal, 1775) }\end{array}$ \\
\hline 2. & Malacopterygii & Chanidae & Chanos & $\begin{array}{c}\text { Chanos chanos (Forskkal, } \\
\text { 1775) }\end{array}$ \\
\hline 3. & Perciformes & Gobiidae & Periothalamus & $\begin{array}{c}\text { Periothalamus sp } \\
\text { (Saanin,1935) }\end{array}$ \\
\hline 4. & Percomorphi & Leloghnatidae & Leignhatus & $\begin{array}{c}\text { Leignhatus dussumieri } \\
\text { (Djuhanda 1981) }\end{array}$ \\
\hline 5. & Percomorphi & Leighathidae & Stolephorus & $\begin{array}{c}\text { Stolephorus } \\
\text { mommersonii } \\
\text { (Djuhanda, 1981) }\end{array}$ \\
\hline 6. & Clupeiformes & Clupeidae & Sardinella & Sardinella longiceps \\
& & & (Bleeker, 1853) \\
\hline
\end{tabular}

Ikan yang di temukan pada hutan mangrove Blok Jati Papak Taman Nasional Alas Purwo dapat di lihat pada tabel 4.1. Di temukan sebanyak 6 famili dan 6 spesies 
di antaranya famili Mugilidae, famili Chanidae, famili Ghobiidae, famili Leloghnatidae, famili Lighathidae dan famili Clupeidae. Sedangkan 6 jenis spesies diantaranya, spesies Valamugil Seheli, spesies Chanoschanos, spesies Periothalamus Sp, spesies Leignhatus Dussumieri, spesies Stolephorus Commersonii dan spesies Sardinella Longiceps. Hasil penelitian menunjukkan bahwa ikan Periothalamus Sp merupakan spesies terbanyak di antara ikan ikan yang lain. Banyaknya spesies Periothalamus $S p$ ini di karenakan periothalamus sp merupakan ikan penetap sejati karena siklus hidupnya berada di daerah ekosistem hutan mangrove (Eddy, 2013).

Dewantoro (2011), menjelaskan bahwa periothalamus sp merupakan kelompok ikan yang sangat dominan baik kepadatan dan keanekaragaman di dalam mangrove. Periothalamus Spakan menyerupai warna dasar perairan dan seringkali membenamkan diri dalam substrat. Hal serupa juga dijelaskan oleh Viqi (2012), di Kawasan Taman Nasional Alas Purwo Periothalamus Spditemukan terbanyak dan dominan dijumpai di Segara Anakan di semua stasiun. Hasil pengamatan menunjukkan adanya adaptasi fauna akuatik yang berada di kawasan Teluk Pangpang Blok jati Papak Taman Nasional Alas Purwo (Nirarita et al. 1996). Yaitu diantaranya spesies Valamugil Seheli dari famili Mugilidae merupakan ikan penetap sementara karena spesies Valamugil selamaperiode anakan hingga dewasa cenderung bergerombol di daerah sepanjang pantai.

Spesies Chanos Chanosdari famili Chanidae, spesies Leignhatus Dussumieridari famili Lelongnathidae dan Stelephorus Commersiniidari famili Leighathidae merupakan ikan pengujung kerena pada periode pasang akan berkunjung pada ekosistem mangrove untuk mencari makan. Spesies Sardinella Longicepsdari faimili Clupeidae merupakan ikan musiman yang mengunakan ekosistem hutan mangrove sebagai tempat perlindungan musiman dari predator (Naririta et al. 1996). 


\subsection{Indeks Kepadatan dan kepadatan Relatif (KR)}

Tabel 3.2 Indeks kepadatan dan kepadatan relatif (KR)

\begin{tabular}{llccccc}
\hline & \multicolumn{1}{c}{ Nama Spesies } & ST1 & ST2 & ST3 & K & KR \\
\hline 1 & Valamugil Seheli & 9 & 4 & 8 & 0,84 & 0,34 \\
\hline 2 & Chanos Chanos & 12 & 4 & 7 & 0,92 & 0,37 \\
\hline 3 & Periothalamus Sp & 39 & 41 & 43 & 4,92 & 1,99 \\
\hline 4 & Leighnatus Dussumieri & 21 & 12 & 9 & 1,68 & 0,68 \\
\hline 5 & Stolephorus Commersonii & 12 & 6 & 6 & 0,96 & 0,39 \\
\hline 6 & Sardinella Longiceps & 6 & 5 & 3 & 0,56 & 0,23 \\
\hline 7 & Total & 99 & 72 & 76 & 9,88 & 4,9
\end{tabular}

Ket: ST1: stasiun $1 \quad$ ST2: stasiun 2 ST3: stasiun 3

K: kepadatan KR: kepadatan relatif

\subsection{Kepadatan Jenis Ikan}

Bedasarkan tabel di atas menunjukkan nilai kepadata tertinggi ditunjukkan oleh Peritiolamus sp yaitu dengan nilai kepadatan 4,9 karena Periostalamus Sptermasuk ikan endemis (asli) sehingga tidak dapat ditemui disembarang tempat. Ikan ini hidup di habitat yang khas yitu daerah intertidal berlumpur (daerah muara sungai yang masih terpngaruh oleh pasang surut). Daerah dengan kriteria tersebut salah satunya adalah ekosistem mangrove, sehingga ikan ini sangat melimpah di mangrove. Periothalamus Sp banyak ditemui di daerah mangrove karena spesies ini memiliki adaptasi khusus yaitu adaptasi respiratorik dan adaptasi morfologis yang sangat mendukung untuk dapat bertahan hidup di lingkungan yang khas dan sangat labil karena terpengaruh pasang surut air laut. Adaptasi respiratorik ditunjukkan oleh modifikasi insang dan kulit yang terlihat dari kemampuannya dapat hidup secara amphibious ketika ikan ini berada didarat. Sedangkan adaptasi morfologis di tunjukkan oleh adaptasi sirip yang menjadikan ikan ini bisa berpegangan pada permukaan vertikal, meloncat di atas lumpur, bahkan berjalan di atas air. Sedangkan nialai kepadatan terendah ditunjukkan oleh SardinellaLongiceps yaitu dengan nilai 
kepadatan 0,6. Sardinella Longiceps adalah ikan pengunjung musiman yang habitatnya ada ditengah perairan, namun ikan ini dapat dijumpai dipermukaan ikan mangrove yaitu pada saat mencari makanan dan mengambil oksigen. Selain itu Sardinella Longiceps menjadikan mangrove sebagai tempat berlindung (Harden Berg, 1935).

\subsection{Kepadatan Relatif (KR) Jenis Ikan}

Berdasarkan tabel di atas menujukkan kepadatan relatif tertinggi ditunjukkan oleh Periothalamus Sp dengan nilai kepadatan relatif 1,99. Sedangkan nilai kepadatan relatif terendah ditunjukkan oleh SardinellaLongiceps dengan nilai kepadatan relatif 0,23. Periothalamus $S p$ memiliki nilai kepadatan tertinggi karena ikan tersebut telah menemukan habitat yang optimum untuk kehidupan yang spesifik, sehingga mampu berkembang biak dengan baik. Periothalamus $S p$ memiliki adaptasi yang baik dan dapat bertahan hidup secara optimal. Sedangkan nilai kepadatan relatif (KR) terendah di tunjukkan oleh Sardinella Longiceps yaitu dengan nilai kepadatan 0,56 dan nilai kepadatan relatif (KR) 0,23 karena Sardinella Longiceps merupakan ikan pengunjung musiman. Meskipun habitatnya ada ditengah perairan, namun ikan ini dapat dijumpai dipermukaan hutan mangrove, yaitu pada saat mencari makanan dan mengambil oksigen Sardinella Longiceps menjadikan mangrove sebagai tempat berlindung, mencari makan dan berkembang biak. Mangrove menyediakan makanan bagi ikan dalam bentuk material organik yang berupa guguran vegetasi tanaman, berbagai jenis serangga, kepiting, udang-udangan dan hewan invertebrata (Nyabakken,1988). Rendahnya spesies ini juga di pengaruhi oleh faktor lingkungan fisik dan kimia perairan yang kurang baik sehingga dapat menyebabkan rendahnya kepadatan sardinella longiceps di daerah penelitian tersebut.

\subsection{Indeks Keanekaragaman}

Tabel 3 Indeks Keanekaragaman jenis ikan bakau

\begin{tabular}{ccc}
\hline Stasiun & $H^{\prime}$ & Makna \\
\hline Stasiunl & 0,36645 & Rendah
\end{tabular}




\begin{tabular}{lll}
\hline Stasiun2 & 0,35934 & Rendah \\
\hline Stasiun3 & 0,36266 & Rendah
\end{tabular}

Keterangan : $\mathrm{H}^{\prime} \leq 1=$ keanekaragaman rendah, $\mathrm{H}^{\prime} \geq 3=$ keanekaragaman sedang

$\mathrm{H}^{\prime} \leq \mathrm{H}^{\prime} \leq=$ keanekaragaman tinggi

Indeks keanekaragaman $\left(\mathrm{H}^{\prime}\right)$ tertinggi terdapat pada stasiun I dengan nilai $\mathrm{H}^{\prime}$ adalah 0,36645. Tingginya keanekaragaman pada stasiun 1 ini disebabkan karena mangrove pada stasiun 1 lebih tebal dibandingkan stasiun 2 dan stasiun 3. Hal tersebut di perkuat oleh viqi (2012) yang menyatakan bahwa tebalnya vegetasi mangrove mengindikasikan keanekaragaman jenis ikan. Selain itu tingginya keanekaragaman pada stasiun 1 menandakan bahwa parameter faktor abiotikyang mendukungseperti suhu, $\mathrm{pH}$ dan salinitas di stasiun 1 tergolong baikuntuk kelangsungan hidup ikan. Menurut Odum (1996) secara umum kisaran suhu yang ideal untuk pertumbuhan makhluk hidup pada umumnya adalah $25-32^{\circ} \mathrm{C}$. Jadi, hasil pengukuran suhu di eksosistem mangrove Blok Jati Papak yang diperoleh dapat dikatakan normal untuk kehidupan ikan yaitu berkisar antara $29-31{ }^{\circ} \mathrm{C}$. Suhu merupakan salah satu parameter penting dalam pertumbuhan dan perkembangan ikan. Selain suhu pH juga berpengaruh terhadap keanekaragaman ikan. Makhluk hidup membutuhkan $\mathrm{pH}$ air antara 6,5 - 8,5 untuk kelangsungan hidup dan reproduksi, pH pada lokasi penelitian berkisar antara 6,9 - 7. Menurut Dharma (1992) menjelaskan bahwa salinitas yang layak untuk kehidupan ikan berada pada kisaran 28 - 34\%o. Salinitas pada lokasi penelitian yaitu berkisar antara 32 - 35 \%o.

Keanekaragaman terendah terdapat pada stasiun 2 dengan indeks keanekaragaman 0,35934. Keanekaragaman rendah diakibatkan oleh jumlah variasi jenis yang ditemukan sedikit, dan ada beberapa jenis yang ditemukan dalam jumlah yang besar, sehingga menyebabkan nilai keanekaragaman pada stasiun 3 kecil. Menurut Adi (2013), bahwa suatu komunitas dikatakan memiliki keanekaragaman yang tinggi jika komunitas itu disusun oleh banyak jenis dengan kelimpahan jenis yang sama atau hampir sama, keanekaragaman dikatakan rendah jika suatu komunitas tersusun atas sedikit jenis dan hanya sedikit jenis yang dominan. Indeks 
keanekaragaman $\left(\mathrm{H}^{\prime}\right)$ merupakan suatu angka yang tidak memiliki satuan dengan kisaran 0 - 3. Tingkat keanekaragaman akan tinggi jika nilai $\mathrm{H}^{\prime}$ lebih dari 3 , sehingga hal ini menunjukkan kondisi perairan tergolong sangatbaik. Sebaliknya jika nilai $\mathrm{H}^{\prime}$ lebih kecil sama dengan 1 maka keanekaragamannya rendah dan kondisi perairan kurang baik bagi kehidupan ikan. Keanekaragaman dapat dikatakan sedang jika nilai $\mathrm{H}^{\prime}$ lebih besar sama dengan 1 tetapi $\mathrm{H}^{\prime}$ lebih kecil sama dengan 3 (Odum, 1993).

Keanekaragaman pada stasiun 1, stasiun 2, dan stasiun 3 teggolong rendah, dapat dilihat dari hasil nilai keanekaragaman berkisar dari 0,35934 - 0,36645. Indeks keanekaragaman rendah menunjukkan bahwa pada lokasi penelitian adanya faktor abiotik yang kurang mendukung bagi kehidupan ikan didaerah tersebut. Salinitas yang melebihi baku mutu air juga dapat mempengaruhi rendahnya keanekaragaman ikan. Salinitas yang layak untuk kehidupan ikan berada pada kisaran 28 - 34\%o. Salinitas pada lokasi penelitian yaitu berkisar antara 32 - 35 \%o (Dharma, 1992).

\section{KESIMPULAN DAN SARAN}

\subsection{Kesimpulan}

Berdasarkan penelitian yang telah dilakukan dapat disimpulkan sebagai berikut:

1. Ikan yang ditemukan pada hutan mangrove dikawasan Teluk Pangpang Blok Jati Papak Taman Nasional Alas Purwo sebanyak 6 jenis spesies diantaranya spesies Valamugil Seheli, spesies Chanoschanos,spesies Periothalamus Sp, spesies Leignhatus Dussumieri, spesies Stolephorus Commersonii dan spesies Sardinella Longiceps.

2. Nilai kepadata dan nilai kepadatan relatif tertinggi terdapat periothalamus $s p$ yaitu dengan nilai kepadatan 4,9 dengan kepadatan relatif (KR) ter 1,99 Nilai kepadatan terendah pada sardinella longiceps dengan nilai 0,56dengan nilai kepadatan relatif (KR) 0,23.

3. Hasil analisis keanekaragaman ikan mangrove pada setiap stasiun menunjukkan bahwa keanekaragaman jenis ikan dikawasan Teluk Pangpang 
Blok Jati Papak Taman Nasional Alas Purwo relatif rendah yaitu pada stasiun 1 nilai berkisar antara $\mathrm{H}^{\prime} \quad$ : 0,36645 pada stasiun 2 nilai berkisar antara $\mathrm{H}^{\prime}: 0,35934$ dan pada satasiun 3 nilai berkisar antara $\mathrm{H}^{\prime}:-0,36266$.

\section{REFERENSI}

Abdullah. 2009, Jenis-jenis Ikan Hasil Tangkapan Nelayan Yang Di Daratkan Di Tempat Pelelangan Ikan (TPI) Kaula Tuha Kecamatan Kaula Pesisir Kabupaten Nagan Raya, FKIP Unsyiah Banda Aceh.

Ainullah. Viqi. M, 2012, Keanekaragaman Jenis Ikan Di Blok Bedul Segoro Anak

Taman Nasional Alas Purwo, FMIPA Universitas Jember.

Andrianto. 2005, Pengaruh Suhu Dan Salinitas Terhadap Keberadaan Ikan.

[SerialOnline] Http://Aryansfirdaus.Wordpress.Com/2010/10/25/Pengaruhsuhu-

Dan- Salinitas-Terhadap-Keberadaan-Ikan/ [Diakses Tanggal 21Maret2012].

Chairuddin. G.T, 199, Keanekaragaman Jenis Ikan Konservasi Di Kawasan Lahan

Basah Sungai Negara. Prosiding Temukarya Ilmiah. Perikanan Rakyat $18-19$

Desember 1989. Pusat Penelitian Dan Pengembangan Perikanan. Badan

Penelitian Dan Pengembangan Pertanian, Jakarta. Hlm:178 - 190.

Dharma.S, 1992, Polusi Air dan Udara. Jakarta : Kanisius.

Dirjen Perikanan Departemen Pertanian 1994 Pengelolaan di Perairan Umum : Dinas Perikanan Jakarta.

Departemen Kelautan dan Perikanan. 2005. Kategori Alat Tangkap Ikan.

Dewantoro. G.W, 2011, Komposisi Jenis Ikan Perairan Mangrove Pada Beberapa Muara Sungai Di Taman Nasional Ujung Kulon, Pandeglang. Banten. Jurnal Fauna Tropika Vol.18 No.2, November 2009. ISSN 0215-191X.

Djuhanda. T, 1981, Dunia Ikan. Amico Bandung.

Eddy. Syaiful, 2 013, Inventarisasi Dan Identifikasi Jenis Ikan Saat Pasang Surut Di Perairan Sungai Musi Kota Palembang, FMIPA Universitas PGRI Palembang.

Effendi. H, 2003, Telaah Kualitas Air bagi Pengelolaan Sumber Daya dan Lingkungan Perairan. Cetakan Kelima. Yogjakarta : Kanisius.

Erwiantono. 2006, Pengantar Ilmu Kelautan. Penerbit Gramedia Widiasarana Indonesia Jakarta.

Guatama. S, 2007, Tujuan Koleksi Ikan. Jakarta.

Gunarto. 2004, Konservasi Mangrove Sebagai Pendukung Sumber Hayati Perikanan Pantai. Jurnal Litbang Pertanian, 23 (1). 15-21.

Harayono. 2009, Buku Panduan Lapangan: Ikan Perairan Lahan Gambut. Penerbit LIPI Press. Jakarta. 
Jasin, M. 1992. Sistematika Hewan. Penerbit Sinar Wijaya, Surabaya. Hlm : 49-217.

Krebs, C.J. 1985. Ecology. The Experiental Analiysys of Distribution and Abudance Edition, Harper \& Row Publishers New York.

Kottelat M , Anthony J. W, Sri Nurani K \& Soetikno W. 1993. Freshwater

Fishes of Western Indonesia and Sulawesi. Jakarta : Periplus Editios (HK)

Latupapua. M. J. J, 2011 Keanekaragaman Nekton di Hutan Mangrove Kawasan Segoro Anakan Taman Nasional Alas Purwo ISSN : 1907-7556, VOL.VI.NO.2.

LIPI . 2010. Ikan di Indonesia. On line at

http://www.biologi.lipi.go.id/bio_english. [akses tanggal 12 Januari

2013 jam 22:34 WIB].

Mason. 1981, Biologi Umum. PT Gramedia Jakarta.

Nyibakken. J.W, 1982, Biologi Laut : Suatu Pendekatan Ekologis. Gramedia Jakarta.

Odum, E, P. 1993. Dasar-Dasar Ekologi (Terjemahan). Gajah Mada University. Yogyakarta.

Patriono. Enggar. Et all, 2001, Inventarisasi Jenis Ikan Di Sungai Ilir Sumatra Selatan, FMIPA Universitas Sriwijaya Palembang.

Prianto. E. dan N. K. Suryati, 2009, Komposisi Jenis dan Potensi Sumber Daya Ikan di Muara Sungai Musi. Jurnal Penelitian Perikanan Indonesia. 16(1):1-8.

Poernomo. 2004, Ekologi Hutan. Jakarta: Bumi Aksara.

Rifai. 1983, Biologi Perikanan 2 Jakarta ; Deroktorat Pendidikan Menengah Kejuruan.

Rustrianto. Buwono. Yanuar, 2015, Potensial Fauna Akuatik Ekosistem Hutan Mangrove Di Kawasan Teluk Pangpang Taman Nasional Alas Purwo Kabupaten Banyuwangi, Universitas Udayana Denpasar.

Saanin. H, 1984. Taksonomi dan Kunci Identifikasi Ikan Jilid II Bina Cipta Bogor, Bogor.

Santa. I, 1988, Biologi Sistematika dan Pemanfaatan Tumbuh-Tumbuhan Universitas Airlangga. Surabaya.

Sari. Antika. Poppy, 2012, Inventarisasi Jenis Ikan (Pisces) Di Pasar Tradisonal Bengkulu Sebagai Alternatif Sumber Belajar Biologi SMA Kelas X, universitas Bengkulu.

Subardja. S. D. M. , 1989, Sistematika Ikan Institut Pertanian. Bogor.

Sulistiono. 2000, Ekobiologi Ikan Fakultas Perikanan dan Kelautan Institut Pertanian Bogor. Bogor.

Soesono. S, 1970, Limnologi. Sekolah Umum Perikanan Menengah Bogor.

Taufik. 2011, Teknik Identifikasi Spesies Ikan. Diakses Tanggal 20 Mei2014. 
Taman Nasional Alas Purwo. 2010, Buletin Manilkara Kauki Taman Nasional Alas Purwo: Vol. 2 Edisi Ii Tahun 2010.

Taman Nasional Alas Purwo. 2012, Taman Nasional Alas Purwo. [Serial Online]Http://Tnalaspurwo.Org/Index.Php/Webpage/Detail/Foto/8 [Diakses Tanggal21maret 2012].

Zonneveld et al., 1991, Prinsip-Prinsip Budidaya Ikan (Terjemahan). PT Gramedia Pustaka Utama Jakarta. 